\title{
Proposições Estratégicas a partir da Análise da Rede de Valor e do Capital Social: um estudo no Polo de Doces de Pelotas - RS
}

\author{
Strategic Propositions Based on the Analysis of the Value \\ Network and Social Capital: a study in the Pole of Candies from \\ Pelotas - RS
}

Jordana Marques Kneipp

Doutoranda em Administração no Programa de Pós-Graduação em Administração, Universidade Federal de Santa Maria - Santa

Maria - RS - Brasil. E-mail: jordanakneipp@yahoo.com.br

Jamur Johnas Marchi

Professor assistente da Universidade Federal do Pampa - Florianópolis - SC - Brasil.E-mail: jamur.marchi@unipampa.edu.br.

Clandia Maffini Gomes

Professora do Departamento de Ciências Administrativas, Universidade Federal de Santa Maria - Santa Maria -- RS - Brasil. E-mail: clandia@smail.ufsm.br

Luciana Aparecida Barbieri da Rosa

Mestre em Administração, Universidade Federal de Santa Maria - Santa Maria - RS - Brasil. E-mail: lucianaaparecidabarbieri@yahoo.com.br

\section{Resumo}

O presente artigo buscou apresentar proposições estratégicas para o Polo de Doces de Pelotas, localizado na Região Sul do Estado do Rio Grande do Sul - RS, a partir do mapeamento da rede de valor e da análise do capital social. O Polo de Doces reúne empresas formais e empreendedores informais ligados ao mercado de doces. A pesquisa caracteriza-se como quantitativa e os dados foram coletados por meio de questionários. Como resultado, percebeu-se que na visão de gestores e integrantes do Polo, a rede de valor é formada por: a) clientes: consumidor final, terceiros e revendedores; b) fornecedores: predominando os atacados; c) concorrentes: destacando-se as grandes doçarias, doces industrializados e o comércio informal; d) complementadores: destacou-se a falta conhecimento sobre os complementadores. De modo geral, constatouse que é necessário obter mais conhecimento sobre os elementos da rede de valor para a geração de vantagens competitivas.

Palavras-chave: Rede de Valor. Capital Social. Coopetição.

\section{Abstract}

This paper aims to present strategic proposals for the Pole of Candies from Pelotas, located in the southern state of Rio Grande do Sul - RS, from the mapping of the value network and analysis of social capital. The cluster brings together formal and informal entrepreneurs linked to the candy market. The research is characterized as quantitative and data were collected through questionnaires. As a result, it was noted that in view of managers and members of the Pole, the value network is comprised of: a) customers, end consumers, contractors and dealers; b) suppliers: predominating wholesale c) competition: highlighting major confectioneries, industrialized sweets and informal trade d) complementors: was emphasized the lack of knowledge about the complementors. Overall, it was found that it is necessary a better understanding of the elements of the value network, to be able to acquire competitive advantages.

Key words: Value Network. Social Capital. Coopetition. 


\section{INTRODUÇÃo}

A competição global pode ser vista em dois movimentos dicotômicos: de um lado, as grandes organizações, que ganham em economia de escala e na subordinação econômica a que submetem os países em desenvolvimento; de outro, as alternativas de desenvolvimento econômico, como parcerias e cooperações entre empresas, nas quais a ação coletiva representa uma estratégia eficaz de sobrevivência, especialmente para micro e pequenas empresas (CASTELLS, 1999; CASAROTTO; PIRES, 2001). Em termos de ação coletiva, discute-se o conceito de capital social, que representa a capacidade de indivíduos e de grupos trabalharem em prol de objetivos comuns ou convergentes. (COLEMAN, 1988; BOISIER, 2000; GROOTAERT, 2003; PUTNAM, 2005)

Considerando alguns estudos sobre políticas de desenvolvimento, destaca-se a importância dos agentes e fatores locais organizados em redes como: distritos industriais, clusters, arranjos de produção locais e de inovação (PORTER, 1989; CASTELLS, 1999; AMATO NETO, 2000; CANEVER et. al., 2004). A valorização da produção local e a sua organização em novas configurações organizacionais baseadas na coopetição integram empresas que buscam conjuntamente vantagens competitivas fundamentadas na complementaridade, na criação de poder de compra, na ampliação da base técnica e de conhecimentos, que de maneira isolada talvez não fosse possível. $\mathrm{O}$ conceito de coopetição pode ser empregado para definir "[...] empresas que competem e cooperam ao mesmo tempo". (LIPNACK; STAMPS, 1994, p. 12; BRANDENBURGER; NALEBUFF, 1996)

O gerenciamento estratégico dessas novas configurações produtivas consiste em um desafio a ser enfrentado pelos seus gestores. Gnyawali e Park (2009) ressaltam a necessidade e a importância de pesquisas que tratem da coopetição em micro e pequenas empresas, em virtude dos benefícios oriundos da colaboração com concorrentes e tendo em vista que grande parte das pesquisas sobre o assunto refere-se às grandes empresas.

Nesse sentido, este trabalho possui como objetivo apresentar proposições estratégicas para o Polo de Doces de Pelotas, localizado na região sul do Estado do Rio Grande do Sul - RS, a partir do mapeamento da sua rede de valor e da análise do seu capital social. O setor de doces de Pelotas é formado por micro e pequenas empresas e organizações informais, as quais atuam coletivamente sob a denominação de Polo.

O trabalho apresenta inicialmente a fundamentação teórica tratando das novas configurações organizacionais, da teoria de rede de valor, do capital social e relacionamentos interorganizacionais e da importância do setor doceiro para a cidade de Pelotas - RS. A seguir segue-se o método para desenvolvimento do estudo, a análise e discussão dos resultados e, por fim, as considerações finais.

\section{Novas Configurações Organizacionais}

No contexto organizacional a dinâmica concorrencial não pode ser mais explicada somente pelo paradigma mecanicista baseado nos pensamentos newtonianos de causalidade linear, nem nas ideias fragmentadoras de Descartes. A competitividade empresarial tornou-se complexa devido à influência dos fenômenos globais que afetam a organização local. De acordo com Castells (1999), organizações e indivíduos estão socialmente envolvidos em teias e redes de relações nas quais a interdependência destes relacionamentos passa a ter relevância. Essas teias de conexões resultam em novas formas organizacionais, que estão baseadas na associação, na complementaridade, no compartilhamento e na ajuda mútua entre os diversos atores que fazem parte destes arranjos.

Esses esforços conjuntos entre empresas assumem diferentes formatos que podem ser observados sob a forma de fusões, join ventures, consórcios, redes empresariais, clusters, polos, entre outros (VINHAS; BECKER, 2006). Segundo Cassiolato e Lastres (2003), novos formatos de associação entre empresas são fundamentais para o enfrentamento dos desafios da era do conhecimento, uma vez que favorecem os processos de aprendizagem coletiva, a cooperação e a dinâmica inovadora. Através desses novos arranjos as empresas procuram desenvolver estratégias para solucionar problemas estruturais e conjunturais buscando vantagens para sobreviver através de ações coletivas, tais como: o aumento do poder de compra, o acesso a novos 
mercados e tecnologias, a melhoria da produtividade $e$ a consequente redução de custos.

Conforme exposto, diversas são as formas de organização coletiva entre empresas, sendo que uma delas denomina-se polo. Para Caporali e Volker (2004) polo representa o conjunto de empresas de um determinado setor em um território. A nomenclatura polo é bastante utilizada pelo Serviço Brasileiro de Apoio às Micro e Pequenas Empresas (SEBRAE) para designar setores nos quais a instituição promove projetos de desenvolvimento em conjunto. Geralmente, um polo abrange as organizações que estão diretamente ligadas à execução do projeto na localidade e também a equipe gestora, os parceiros, os governos locais e os beneficiários, isto é, todos os atores que, direta ou indiretamente, interferem nas atividades desenvolvidas no local. É relevante destacar que o objeto deste estudo é um setor no qual o SEBRAE desenvolve ações $e$ enquadra-se no conceito apresentado.

\section{Formulação de Estratégias a partir da Rede de Valor}

No contexto da administração estratégica concorrencial, Porter (1989) destaca que o grau de concorrência depende de cinco forças competitivas básicas, que estão em constante conflito, que são: entrantes potenciais, produtos ou bens substitutos, compradores, fornecedores e concorrentes atuais. Porter $(1989$, p. 06), salienta que "[...] clientes, fornecedores, substitutos e os entrantes potenciais, são todos concorrentes para as empresas podendo ter maior ou menor importância". Essa visão transmite a sensação de que no ambiente não há nenhum ator/jogador que possa contribuir positivamente para a empresa, nem mesmo os clientes, pois eles disputam por preços menores tornando-se assim concorrentes, todos os players são vistos como uma ameaça e as relações como jogos de soma-zero.

Por outro lado, os conceitos de cooperação/competição de Nalebuff e Brandenburger (1996) adotam a abordagem de guerra e paz, ou seja, cooperar na criação de um mercado e competir na sua divisão, isso simultaneamente, adotando assim o termo coopetição para melhor definir esta relação. Como o relacionamento entre empresa, clientes, fornecedores e concorrentes são geralmente repetitivos vale destacar a importância de existir cooperação ou complementação entre tais atores, visando um ganho maior para todos sem que necessariamente alguns jogadores/atores saiam prejudicados, aumentando assim os benefícios para todas as partes, configurando nesse sentido jogos de soma não zero.

Segundo Azevedo, Carvalho e Silva (2003) os jogos de soma zero são aqueles em que a soma final dos benefícios e prêmios resultantes das ações dos jogadores durante o jogo (payoffs) se mantém constante, sendo que independentemente da ação dos jogadores não existe criação ou perda nos valores adicionados. Já nos de soma não zero, as ações dos jogadores irão modificar o valor adicionado global e a soma final dos payoffs não se mantém constante. Jogos em que o ganho de um jogador implica necessariamente na perda para o outro, constitui os chamados "jogos estritamente competitivos" ou "jogos de soma zero". Já nos jogos de soma não zero, os jogadores ou equipes não desempenham papéis contrários um ao outro, mas jogam juntos, a fim de maximizar seus benefícios ou minimizar suas perdas (WAIZBORT, 2005; LEONETI; OLIVEIRA; OLIVEIRA, 2010). Em síntese, o que distingue esses dois tipos de jogos é que nos de soma zero obrigatoriamente alguém sai prejudicado. Já nos jogos de soma não zero todos os players tendem a alcançar algum benefício, em algum momento.

Atualmente, o sucesso de um negócio pode requerer que as empresas sigam as duas estratégias simultaneamente (LADO et al., 1997). A cooperação possibilita o acesso a ativos que uma empresa isoladamente, teria dificuldade em obter. Por outro lado, a competição é importante para manter a tensão criativa dentro das organizações e evitar o conluio, pressionando-se mutuamente na busca pelo desenvolvimento. (BENGTSSON; KOCK, 1999)

Nesse sentido, estratégias coopetitivas fornecem uma abordagem paradoxal, uma vez que tradicionalmente, as teorias de competição e cooperação fazem parte de diferentes e antagônicas correntes teóricas (GARCIA; VELASCO, 2002). A coopetição presume que as empresas possam se beneficiar simultaneamente das estratégias de cooperação e competição e ainda, que ambas ocorram ao mesmo tempo.

Os principais benefícios da coopetição incluem uma combinação de competências e recursos para criar sinergias e economias de escala, redução de incertezas 
e riscos, e redução do tempo no desenvolvimento de tecnologias e produtos. (GNYAWALI; PARK, 2009)

Segundo Armstrong (1997) e Ghemawat (2007), para visualizar as possibilidades estratégicas, a contribuição relevante de Nalebuff e Brandenburger (1996), consiste na criação da rede de valor. A Figura 1 apresenta o modelo ou mapa esquemático do jogo dos negócios, denominado de rede de valor. O objetivo do modelo é facilitar a visualização de todo o jogo, pois, focalizar um único tipo de jogador ou um único tipo de relacionamento, tende a produzir pontos cegos.

A rede de valor apresenta um quadro mais completo do jogo de negócios, explorando os papéis dos quatro tipos jogadores: clientes, fornecedores, concorrentes e complementadores $e$ as interdependências entre eles. A partir do mapeamento da rede de valor o gestor terá maior clareza de qual é o papel que cada um dos players desempenha junto à organização e quais são as possibilidades de aprimorar os relacionamentos e ainda de propor novos relacionamentos estratégicos. $\mathrm{Na}$ dimensão vertical da rede de valor encontram-se os clientes e os fornecedores e na dimensão horizontal os concorrentes e complementadores.

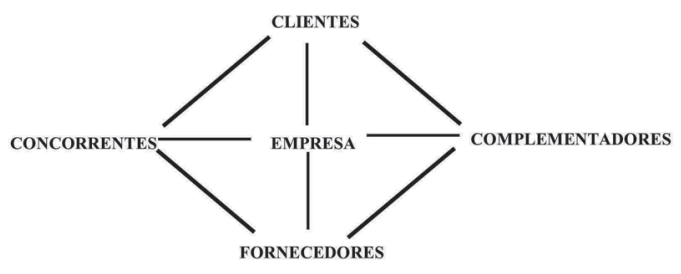

Figura 1: Rede de valor

Fonte: Brandenburguer e Nalebuff (1996, p. 29)

Tendo em vista que a parte superior da rede trabalha com os clientes pode-se dizer que: um jogador é complementador quando o cliente valoriza mais determinado produto seu quando possui o que o outro jogador oferece do que quando não possui; um jogador é concorrente quando o cliente valoriza menos determinado produto seu quando possui o que o outro jogador oferece do que quando não possui. $\mathrm{Na}$ parte inferior da rede, para os fornecedores, as definições são as seguintes: um jogador é complementador quando é mais interessante para o fornecedor oferecer-lhe recurso, quando também está suprindo outro jogador, do que quando não está; um jogador é concorrente quando é menos interessante para o fornecedor oferecer-lhe recursos quando também está suprindo outro jogador do que quando não está. (BRANDENBURGUER; NALEBUFF, 1996)

Teoricamente, a rede de valor foi criada para empresas. No entanto, Costa (2007) apresenta uma aplicação da rede de valor em um cluster, de forma genérica. Afirma que para um cluster os jogos cooperativos estão mais ligados aos seus clientes, complementadores $e$ fornecedores. Por outro lado, a competição ocorre entre clusters. Contudo, não descarta a possibilidade de que cada empresa dentro de um cluster estabeleça suas estratégias competitivas e cooperativas, considerando clientes internos e externos, fornecedores internos e externos, bem como concorrentes internos e externos (COSTA, 2007). Nesse trabalho, considerou-se o polo como um tipo de cluster e procurou-se identificar os seus fornecedores, clientes, complementadores e competidores.

\section{Capital Social e Relacionamentos INTERORGANIZACIONAIS}

Nas últimas décadas, o estudo do capital social tem se difundido e ganhado espaço em vários campos das ciências sociais, sendo que sua base conceitual apresenta-se de forma bastante heterogênea, sendo difícil encontrar uma única definição (OLIVEIRA et. al., 2007). As boas relações sociais entre diversos agentes podem constituir um tipo de capital que pode trazer vantagens para os membros que se inter-relacionam. Agrupando algumas definições existentes, pode-se dizer que o conceito de capital social gira em torno de duas correntes representadas pelos autores Ronald Burt e Robert Putnam.

A corrente de Burt (2001) está ligada a informações, ideias e apoios, nas quais os indivíduos podem se sustentar em decorrência de suas relações com outras pessoas. $\mathrm{O}$ acesso aos recursos depende da rede de relacionamento, uma vez que aqueles que detêm as melhores posições dentro dessas redes e ligações com vários grupos possuem maior capital social do que seus pares (GROOTAERT et al., 2003). A linha de pensamento de Burt (2001) defende que quanto mais alta a posição ocupada dentro do grupo maior o capital social. A corrente de Putnam (2005, p. 177) relaciona "[...] o capital social com características da organização como confiança, normas e sistemas, que 
contribuam para o aumento da eficiência da sociedade, facilitando as ações coordenadas".

Caporali e Volker (2004) definem capital social como um conjunto de normas e valores que conduzem as interações entre os indivíduos, incluindo as instituições que governam a sociedade. $\mathrm{O}$ capital social permite que os membros de um grupo confiem uns nos outros e possam cooperar na formação de novos grupos ou realizar ações em comum. (BOISIER, 2000)

O capital social pode reduzir os custos de transação, permitir a existência de instituições estáveis, facilitar a gestão de conflitos, limitar as práticas monopolistas e assegurar que as infrações sejam penalizadas e, portanto, desencorajadas. Em particular, essa redução de custos de transação acelera a transmissão da informação no que diz respeito à difusão e imitação das boas práticas, aumentando assim, a sinergia entre o grupo de empresas que trabalham em conjunto. (CAPORALI; VOLKER, 2004)

Para avaliar a presença ou ausência de capital social, ou mesmo a sua possibilidade de formação, pesquisas realizadas para o Banco Mundial por Grootaert et al. (2003), desenvolveram o Integrated questionnaire for the measurement of social capital (SC-IQ). Como o capital social é frequentemente, definido em termos dos grupos, das redes, das normas e da confiança, o questionário foi proposto a fim de englobar essa multidimensionalidade, incluindo seis dimensões fundamentais: grupos e redes, confiança $e$ solidariedade, ação coletiva e cooperação, informação e comunicação, coesão e inclusão social, e autoridade e ação política. Uma síntese dessas dimensões é apresentada no Quadro 1.

\begin{tabular}{|c|c|c|}
\hline Categorias & Significado E OBJETIVo & Dimensões \\
\hline Grupos e redes & $\begin{array}{l}\text { Medida do capital social estrutural que parte } \\
\text { do pressuposto de que o capital social facilita } \\
\text { a tomada de decisão coletiva, pois ajuda a } \\
\text { disseminar informações e reduz comportamentos } \\
\text { oportunistas. }\end{array}$ & $\begin{array}{l}\text { Grupos } \\
\text { - densidade e diversidade de associação; } \\
\text { - nível de funcionamento democrático; e } \\
\text { - extensão da conexão com outros grupos. } \\
\text { Redes } \\
\text { - tamanho e diversidade interna da rede; e } \\
\text { - até que ponto se daria assistência em caso de } \\
\text { necessidade; }\end{array}$ \\
\hline $\begin{array}{l}\text { Confiança e } \\
\text { solidariedade }\end{array}$ & $\begin{array}{l}\text { Medida do capital social cognitivo que procura } \\
\text { identificar o grau de confiança em geral e no } \\
\text { contexto de transações específicas. }\end{array}$ & $\begin{array}{l}\text { - até que ponto se confia nas pessoas em geral e - } \\
\text { até que ponto se confia nas pessoas envolvidas em } \\
\text { transações específicas; }\end{array}$ \\
\hline $\begin{array}{l}\text { Ação coletiva e } \\
\text { cooperação }\end{array}$ & $\begin{array}{l}\text { Parte do pressuposto de que na grande maioria } \\
\text { das localidades, a ação coletiva só é possível } \\
\text { quando há um nível significativo de capital social } \\
\text { disponível a comunidade. }\end{array}$ & $\begin{array}{l}\text { - a ação coletiva; } \\
\text { - o tipo de atividades desenvolvidas coletivamente; e } \\
\text { - a percepção a cerca da iniciativa para cooperar e } \\
\text { participar de ações coletivas. }\end{array}$ \\
\hline $\begin{array}{l}\text { Informação e } \\
\text { comunicação }\end{array}$ & $\begin{array}{l}\text { Investiga a disponibilidade e quantidade de } \\
\text { meios de comunicação e fontes de informação à } \\
\text { disposição dos membros da comunidade. }\end{array}$ & $\begin{array}{l}\text { - fontes de informação e os meios de comunicação tais } \\
\text { como: telefones, jornais, rádio, televisão, etc. }\end{array}$ \\
\hline $\begin{array}{l}\text { Coesão e inclusão } \\
\text { social }\end{array}$ & $\begin{array}{l}\text { Procura identificar a inclusão e exclusão social e } \\
\text { a predominância do capital social de ponte ou de } \\
\text { ligação. }\end{array}$ & $\begin{array}{l}\text { - inclusão: acesso a educação, saúde e justiça; } \\
\text { - sociabilidade: encontro com pessoas em espaços } \\
\text { públicos, visitas, eventos, etc.; } \\
\text { - conflito e violência: o grau e o tipo de violência, a } \\
\text { contribuição da divisão interna da comunidade e os } \\
\text { sentimentos de insegurança, originados pelo medo. }\end{array}$ \\
\hline $\begin{array}{l}\text { Autoridade ou } \\
\text { capacitação } \\
\text { (empowerment e } \\
\text { ação política) }\end{array}$ & $\begin{array}{l}\text { Refere-se à expansão dos recursos das capacidades } \\
\text { das pessoas em tomar parte, negociar, influenciar, } \\
\text { controlar e responsabilizar-se pelas instituições que } \\
\text { afetam suas vidas e mede a habilidade das pessoas } \\
\text { em ampliar o seu grau de autoridade e capacitação } \\
\text { e a sua ação política. }\end{array}$ & $\begin{array}{l}\text { Autoridade ou capacitação } \\
\text { - habilidade em tomar decisões que afetam as atividades } \\
\text { cotidianas e que podem mudar o curso de suas vidas. } \\
\text { Ação política } \\
\text { - escrever petições; } \\
\text { - participar de reuniões com políticos; } \\
\text { - participar de demonstrações e campanhas; } \\
\text { - votar em eleições. }\end{array}$ \\
\hline
\end{tabular}

Quadro 1: Categorias e dimensões do capital social

Fonte: Oliveira et al. (2007, p. 6) e Grootaert et al. (2003) 
O Integrated Questionnaire for the measurement of Social Capital (SC-IQ) foi construído com foco na avaliação do capital social de comunidades. Em uma tentativa de avaliar o relacionamento entre atores que formam e atuam em redes empresariais, Marchi (2006) utilizaram quatro fatores sócio-comportamentais: confiança, cooperação, comprometimento e conexões, conforme o Quadro 2. Esses fatores foram segmentados em duas variáveis cada, sendo que cada variável foi avaliada por três questões.
A ideia procurou considerar que uma rede empresarial também emerge de uma construção social entre diversos atores (PODOLNY; PAGE, 1998), sendo que no atual paradigma da coopetição, fatores sociais $e$ comportamentais se tornam relevantes para o sucesso de estratégias coletivas (BORGATTI; FOSTER, 2003). $\mathrm{O}$ trabalho verificou a relevância desses fatores para a sustentação da estratégia de redes e a possível influência no desenvolvimento dessas organizações.

\begin{tabular}{|c|c|c|}
\hline Categorias & VARIÁVEIS & Questões \\
\hline \multirow{2}{*}{ Confiança } & Dimensão externa & $\begin{array}{l}\text { - Confiança em relação à maioria dos participantes da rede; } \\
\text { - Confiança em relação à direção central da rede; } \\
\text { - Percepção do aumento da confiança mútua; }\end{array}$ \\
\hline & Dimensão interna & $\begin{array}{l}\text { - Confiança nas promessas de outra pessoa; } \\
\text { - Confiança atribuída a primeira vez que se conhece uma pessoa; } \\
\text { - Confiança atribuída depois de conhecer uma pessoa; }\end{array}$ \\
\hline \multirow{2}{*}{ Cooperação } & Ajuda mútua & $\begin{array}{l}\text { - Percepção das atitudes de ajuda mútua; } \\
\text { - Cooperação mesmo sem obter benefícios diretos ou no curto prazo; } \\
\text { - Percepção da cooperação em situações de crise; }\end{array}$ \\
\hline & Rotulagem & $\begin{array}{l}\text { - Percepção do grau de oportunismo; } \\
\text { - Percepção do grau de individualismo; } \\
\text { - Percepção do grau de reputação; }\end{array}$ \\
\hline \multirow{2}{*}{ Comprometimento } & Engajamento & $\begin{array}{l}\text { - Percepção quanto ao engajamento dos outros nas atividades; } \\
\text { - Frequência em reuniões, assembleias e outras atividades; } \\
\text { - Percepção em relação ao comprometimento dos outros; }\end{array}$ \\
\hline & $\begin{array}{l}\text { Compromissos com } \\
\text { acordos }\end{array}$ & $\begin{array}{l}\text { - Valor dos mecanismos de punitivos para o cumprimento de acordos; } \\
\text { - Percepção quanto ao cumprimento dos acordos; } \\
\text { - Percepção quanto ao não cumprimento dos acordos; }\end{array}$ \\
\hline \multirow{2}{*}{ Conexões } & Internas & $\begin{array}{l}\text { - Frequência de conexões internas; } \\
\text { - Frequência do recebimento de informações (boletim informativo, e-mail); } \\
\text { - Grau de bons relacionamentos internos; }\end{array}$ \\
\hline & Externas & $\begin{array}{l}\text { - Grau de conexões externas relevantes para o negócio; } \\
\text { - Frequência de conexões externas relevantes; } \\
\text { - Grau de não redundância nas conexões externas. }\end{array}$ \\
\hline
\end{tabular}

Quadro 2: Questões para mensurar fatores sócio-comportamentais em redes empresariais

Fonte: Marchi (2006)

Para Putnam (2005, p. 180) "[...] a confiança promove a cooperação, sendo que quanto mais elevado o nível de confiança em uma comunidade, maior a probabilidade de haver cooperação". Marchi (2006) enfatizam que o comprometimento representa o engajamento dos atores nas atividades da rede, evidenciando o envolvimento e interesse nas questões comuns do grupo. Bons relacionamentos internos $e$ bons contatos externos são destacados por Lipnack e Stamps (1994) e Burt (2001), pois viabilizam a coesão interna e a renovação das informações relevantes para a rede, aumentado a competitividade.

O capital social se refere à experiência associativa, aos laços de confiança e de cooperação, as competências e habilidades organizacionais, $e$ as configurações tácitas ou institucionalizadas que capacitam os relacionamentos interpessoais e interorganizacionais, que são importantes para a construção social. (MACKE; DILLY, 2010) 
Chin, Chan e Lam (2008) identificam a gestão da liderança e o desenvolvimento da confiança como os principais fatores críticos de sucesso na gestão estratégia da coopetição. Neves et al. (2011) ressaltam como elementos-chave para o processo de coopetição, no que se refere as estratégias de cooperação: confiança e reciprocidade, complementaridade e comprometimento, troca de experiências e aprendizagem, histórico $e$ identidade, adaptabilidade e alinhamento, interdependência e igualdade. E vinculados às estratégias de competição, identificaram os seguintes elementos: incompatibilidade e conflitos, concorrência e rivalidade, controle e padronização, desempenho individual e coletivo $e$ independência e autonomia.

As dificuldades em mensurar o capital social são inúmeras, uma vez que consiste em um elemento intangível, constituído por uma série de fatores e está relacionado a um grupo de pessoas e organizações. Porém, a sua importância é fundamental para a construção de um relacionamento sólido e sucesso do grupo.

\section{A Importância do Setor Doceiro para a Cidade de Pelotas - RS}

A cidade de Pelotas localiza-se na região sul do Estado do Rio Grande do Sul - RS e o doce é parte da história e das transformações tecnológicas, dos diferentes momentos sociais, econômicos e culturais do município (LODY, 2003, p. 12). A tradição doceira da cidade remonta o ciclo do charque, um dos mais promissores períodos da história do Rio Grande do Sul, $e$ foi influenciada pelos imigrantes portugueses, que trouxeram consigo a sua paixão e gosto pelo doce. De acordo com Lody (2003), no século XIX, Pelotas recebe a memória e o patrimônio dos doces portugueses, uma vez que a cidade foi colonizada, especialmente por imigrantes do Aveiro.

Durante o século XIX, o doce ocupou os palacetes de Pelotas tornando-se um hábito local, devido a três motivos: a) os colonizadores eram portugueses ou descendentes de portugueses e trouxeram de Portugal o gosto pelo doce; b) a população da cidade, devido à excelente condição financeira, primava pelo requinte social, promovendo festas, banquetes, saraus, entre outros; c) a condição de charqueadores tornava fácil a importação de açúcar do Nordeste nos mesmos navios que levavam o charque. A cidade de Pelotas exportava charque e, através de troca, importava o açúcar, vindo do Nordeste, e assim as próprias mucamas em parceria com as sinhás o transformavam em deliciosas sobremesas adaptadas ao gosto local. (MAGALHÃES, 2003)

Com a chegada de imigrantes de outros países, no século XIX, incorporaram-se à tradição doceira novos costumes e novas técnicas. É nessa época que se intensificou o plantio de frutas de clima temperado como pêssego, maçã, figo e marmelo e, pouco depois, essas frutas foram utilizadas para fazer compotas, doces de massa, passas e cristalizados (MAGALHÃES, 2003). Segundo Betemps (2003), os franceses sempre cultivaram frutas em seus pomares, tendo como costume a prática de produzir conservas de frutas. A criatividade desses imigrantes trouxe a cidade de Pelotas uma nova maneira de consumir as frutas, que aliada à tradição doceira portuguesa representou os primeiros passos para a região ser conhecida como grande produtora de frutas e doces.

A cidade de Pelotas - RS é considerada a Capital Nacional do Doce e sedia a Feira Nacional do Doce (Fenadoce), que consiste em um evento de grande porte e de caráter internacional e acontece anualmente desde 1986, organizado pela Câmara de Dirigentes Lojistas (CDL). O segmento doceiro artesanal de Pelotas responde por um faturamento estimado em 7 milhões e estima-se a venda de 150.000 unidades de doces por mês nos períodos de pico. O número de postos de trabalho chega a cinco mil ao longo de toda a cadeia produtiva (CANEVER et. al., 2004). Esses números exemplificam o potencial do setor e a sua representatividade para a cidade de Pelotas, pois envolvem um grande número de atores, empreendedores formais e informais que movimentam parte da economia local.

\section{Método para Desenvolvimento do Estudo}

A presente pesquisa caracteriza-se como descritiva e quantitativa e teve como objetivo apresentar proposições estratégicas para o Polo de Doces de Pelotas - RS, a partir do mapeamento da rede de valor e da análise do capital social. 


\subsection{Unidade de Análise}

O estudo foi realizado no Polo de Doces da cidade de Pelotas - RS. O Polo de Doces iniciou como um projeto de desenvolvimento setorial do SEBRAE Sul em 2005, e é composto por empreendedores do mercado de doces, abrangendo tanto empresas formais como doceiros informais. Estes atores produzem doces de confeitaria e doces artesanais de frutas, em diferentes escalas de produção e que atingem diversos mercados. O objetivo do Polo consiste em promover e organizar o setor de doces de Pelotas, por meio da capacitação de empresas, melhorando a qualidade dos produtos e processos, possibilitando o desenvolvimento e crescimento das empresas. O projeto possui uma equipe gestora, composta por um técnico do SEBRAE, uma consultora da instituição e uma supervisora geral. $\mathrm{O}$ Polo é composto por 38 empresas formais, 21 empre- endedores informais e 3 gestores, o que caracteriza a população-alvo da pesquisa.

\subsection{Modelo Conceitual}

Para análise da rede de valor do Polo de Doces utilizou-se o modelo proposto por Nalebuff e Brandenburger (1996), que explora os papéis de quatro tipos de jogadores: clientes, fornecedores, concorrentes e complementadores e as interdependências entre eles. Por meio dos modelos para avaliar o capital social (Quadro 1) e os fatores sociocomportamentais (Quadro 2) procurou-se adequar um modelo de investigação coerente com a realidade das empresas do Polo de Doces. Para tanto, sintetizou-se a proposta em quatro dimensões: confiança, cooperação, comprometimento e conexões e adequaram-se as variáveis e as questões, conforme o Quadro 3.

\begin{tabular}{|c|c|c|}
\hline Categorias & VARIÁVEIS & Procura identificar \\
\hline \multirow[t]{2}{*}{ Confiança } & $\begin{array}{l}\text { Dimensão } \\
\text { externa }\end{array}$ & $\begin{array}{l}\text { - A confiança em relação à maioria dos integrantes } \\
\text { - O grau de confiança em relação aos gestores } \\
\text { - A confiança percebida nos últimos meses entre os integrantes do Polo }\end{array}$ \\
\hline & $\begin{array}{l}\text { Dimensão } \\
\text { interna }\end{array}$ & $\begin{array}{l}\text { - O grau de confiança inicial com relação a um novo integrante } \\
\text { - A confiança com o passar do tempo }\end{array}$ \\
\hline Cooperação & Ajuda mútua & $\begin{array}{l}\text { - O nível de cooperação (ajuda mútua) entre os integrantes do grupo } \\
\text { - A contribuição para um projeto sem benefícios diretos } \\
\text { - O nível de cooperação em situações de crise }\end{array}$ \\
\hline Comprometimento & Engajamento & $\begin{array}{l}\text { - O grau de envolvimento dos integrantes nas atividades } \\
\text { - O grau de envolvimento individual } \\
\text { - Cumprimento das atividades com relação à maioria dos integrantes } \\
\text { - Atuação individual com relação ao cumprimento das atividades }\end{array}$ \\
\hline \multirow[t]{2}{*}{ Conexões } & $\begin{array}{l}\text { Conexões } \\
\text { internas }\end{array}$ & $\begin{array}{l}\text { - O nível de bons relacionamentos } \\
\text { - O compartilhamento de informações entre os membros do grupo } \\
\text { - A frequência de contato com os outros integrantes } \\
\text { - A frequência de recebimento de informações }\end{array}$ \\
\hline & $\begin{array}{l}\text { Conexões } \\
\text { externas }\end{array}$ & $\begin{array}{l}\text { - Pessoas ou entidades que fornecem informações relevantes para a empresa e não fazem } \\
\text { parte do Polo }\end{array}$ \\
\hline
\end{tabular}

Quadro 3: Síntese do modelo para avaliar o capital social no Polo

Fonte: Adaptado de Grootaert et al. (2003) e Marchi (2006)

\subsection{Coleta e Análise dos Dados}

Para a coleta de dados, elaborou-se um questionário semiestruturado baseado na revisão da literatura. O questionário dividiu-se em três blocos: rede de valor, capital social e contribuições, limitações e sugestões para o Polo de Doces. O instrumento de coleta de dados adotou uma escala do tipo likert de cinco pontos, na qual 1 representava muito baixo e 5 muito alto. Segundo Hair et al. (2005), esse tipo de escala é usada para mensurar conceitos na pesquisa em administração. 
Os dados foram coletados durante o primeiro semestre de 2008. O questionário foi aplicado aos gestores e também as empresas formais e aos empreendedores informais do Polo. Foram entrevistados dois gestores e dos 59 cadastrados no Polo obteve-se um retorno de 25 empresas formais e 12 informais, ou seja, $62,7 \%$ da população-alvo. Os dados foram tabulados e analisados com o auxílio dos softwares Sphinx Léxica ${ }^{\circledast}$ e Microsoft Office Excel ${ }^{\oplus}$, por meio de análise estatística univariada.

\section{Apresentação e Discussão dos Resultados}

Inicialmente, são apresentados os resultados referentes ao mapeamento da rede de valor e a seguir os relacionados ao capital social do Polo de Doces de Pelotas - RS.

\subsection{Rede de Valor do Polo de Doces de Pelotas - RS}

Para mapear a rede de valor do Polo de Doces foram identificados os seus principais players, na visão dos atores e gestores do Polo. Para tanto, os respondentes da pesquisa, listaram os seus principais concorrentes, fornecedores, clientes e complementadores. Para fins deste estudo, os nomes originais de empresas foram substituídos por denominações fictícias. A Tabela 1 evidencia os principais concorrentes do Polo de Doces de Pelotas.

Os resultados demonstram que os principais concorrentes que compõem a rede de valor do Polo de Doces de Pelotas, são doçarias da própria cidade, que ainda não pertencem ao grupo. A Tabela 2 evidencia os principais fornecedores do Polo de Doces de Pelotas.

Os resultados evidenciam que os doceiros preferem fornecedores locais, já que as quatro primeiras posições referentes aos principais fornecedores são ocupadas por atacados da cidade. Na Tabela 3 apresentam-se os principais clientes do Polo de Doces de Pelotas.
Tabela 1: Principais concorrentes na concepção dos doceiros

\begin{tabular}{|c|c|c|}
\hline Principais Concorrentes & $\mathbf{F}(\mathrm{N})$ & $F(\%)$ \\
\hline Doçaria A & 17 & 14,2 \\
\hline Doçaria B & 14 & 11,7 \\
\hline Doçaria C & 8 & 6,7 \\
\hline Doçaria D & 6 & 5,0 \\
\hline Doçaria E & 5 & 4,2 \\
\hline Doçaria F & 4 & 3,3 \\
\hline Doçaria G & 4 & 3,3 \\
\hline Doçaria H & 4 & 3,3 \\
\hline Doçaria I & 4 & 3,3 \\
\hline Doçaria J & 3 & 2,5 \\
\hline Doçaria L & 3 & 2,5 \\
\hline Outros $^{1}$ & 48 & 40,0 \\
\hline Total & 120 & 100,0 \\
\hline
\end{tabular}

1 Foram agrupadas as citações com frequência inferior a 3

Fonte: Dados da pesquisa

Tabela 2: Principais fornecedores na concepção dos doceiros

\begin{tabular}{|c|c|c|}
\hline Principais Fornecedores & $\mathbf{F}(\mathrm{N})$ & $\mathbf{F}(\%)$ \\
\hline Atacado A & 18 & 11,5 \\
\hline Atacado B & 14 & 9,0 \\
\hline Atacado C & 13 & 8,3 \\
\hline Atacado D & 11 & 7,1 \\
\hline Empresa A & 7 & 4,5 \\
\hline Empresa B & 6 & 3,8 \\
\hline Empresa C & 6 & 3,8 \\
\hline Empresa D & 6 & 3,8 \\
\hline Empresa E & 3 & 1,9 \\
\hline Empresa F & 3 & 1,9 \\
\hline Outros $^{1}$ & 69 & 44,2 \\
\hline Total & 156 & 100,0 \\
\hline
\end{tabular}

1 Foram agrupadas as citações com frequência inferior a 3.

Fonte: Dados da pesquisa 
Tabela 3: Principais clientes do Polo de Doces na concepção dos doceiros

\begin{tabular}{|l|c|c|}
\hline \multicolumn{1}{|c|}{ Principais Clientes } & F(N) & F(\%) \\
\hline Consumidor Final & 30 & 22,4 \\
\hline Terceiros/ Revendedores & 5 & 3,7 \\
\hline Padarias & 5 & 3,7 \\
\hline Doçaria A & 3 & 2,2 \\
\hline Doçaria B & 3 & 2,2 \\
\hline Doçaria C & 3 & 2,2 \\
\hline Escolas & 3 & 2,2 \\
\hline Feiras em outras cidades & 3 & 2,2 \\
\hline Instituições de Ensino Superior & 3 & 2,2 \\
\hline Restaurantes & 3 & 2,2 \\
\hline Outros & 73 & 54,5 \\
\hline Total & 134 & 100,0 \\
\hline
\end{tabular}

Fonte: Dados da pesquisa

De acordo com os dados da pesquisa, evidencia-se que o principal cliente do Polo de Doces é o consumidor final. A seguir aparecem os "terceiros", que são aqueles que revendem os doces, e também as padarias que compram dos produtores de doces para posterior revenda no estabelecimento comercial. Por fim, na Tabela 4 são apresentados os complementadores do Polo de Doces.

Os resultados denotam que o principal complementador do Polo de Doces consiste na Feira Nacional do Doce (Fenadoce). Ressalte-se que a feira reúne diversas atividades complementares ao consumo de doces, desse modo, cada expositor precisa agregar valor ao produto e demonstrar os seus diferenciais $e$ também atuar em conjunto com os demais expositores. $\mathrm{Na}$ feira, os clientes compram produtos ou serviços complementares, bem como os fornecedores vendem recursos complementares.

Também se destaca como complementador a época do Natal, demonstrando que os doceiros vislumbram maiores oportunidades de negócio em função das festividades da época. Além de muitos consumidores comprarem doces para a ceia, também é possível personalizar os produtos com motivos natalinos e atuar em parceria com supermercados, lojas de presentes e empresas visando o oferecimento de doces para as confraternizações de final de ano. Os doceiros
Tabela 4: Principais complementadores do Polo de Doces na opinião dos doceiros

\begin{tabular}{|l|c|c|}
\hline \multicolumn{1}{|c|}{ Principais CoMPLEMENTADORES } & F(N) & F(\%) \\
\hline Fenadoce & 20 & 14,4 \\
\hline Natal & 10 & 7,2 \\
\hline Inverno & 9 & 6,5 \\
\hline Qualidade & 9 & 6,5 \\
\hline Datas Comemorativas & 8 & 5,8 \\
\hline Formaturas & 6 & 4,3 \\
\hline Eventos & 4 & 2,9 \\
\hline Feiras em outras cidades & 4 & 2,9 \\
\hline Casamentos & 3 & 2,2 \\
\hline Feira do Livro & 3 & 2,2 \\
\hline Festas & 3 & 2,2 \\
\hline Morango & 3 & 2,2 \\
\hline Padronização & 3 & 2,2 \\
\hline Apresentação & 3 & 2,2 \\
\hline Atendimento & 3 & 2,2 \\
\hline Festas de Final de Ano & 39,4 \\
\hline Outros & 3 & 100,0 \\
\hline Total & 3 & \\
\hline
\end{tabular}

Fonte: Dados da pesquisa

também apontam o Inverno como complementador, pois acreditam que nessa época do ano ocorre grande parte dos eventos da cidade e também as pessoas ficam mais propensas ao consumo de doces.

A Figura 2 aponta os cinco principais atores identificados pelos respondentes em cada categoria, resumindo a rede de valor do Polo de Doces de Pelotas, com base no modelo de Brandenburguer e Nalebuff (1996).

Na visão dos doceiros, os seus concorrentes são as próprias doçarias da cidade; os clientes são o consumidor final, os terceiros/revendedores, as próprias doçarias concorrentes e as escolas. Os fornecedores configuram-se em atacados locais e, os complementadores são eventos, datas e épocas do ano.

Para ratificar a rede de valor concebida pelos integrantes do Polo e refletir sobre possíveis estratégias coopetitivas, entrevistou-se a sua equipe gestora. $\mathrm{Na}$ concepção dos gestores, a rede de valor do Polo de 


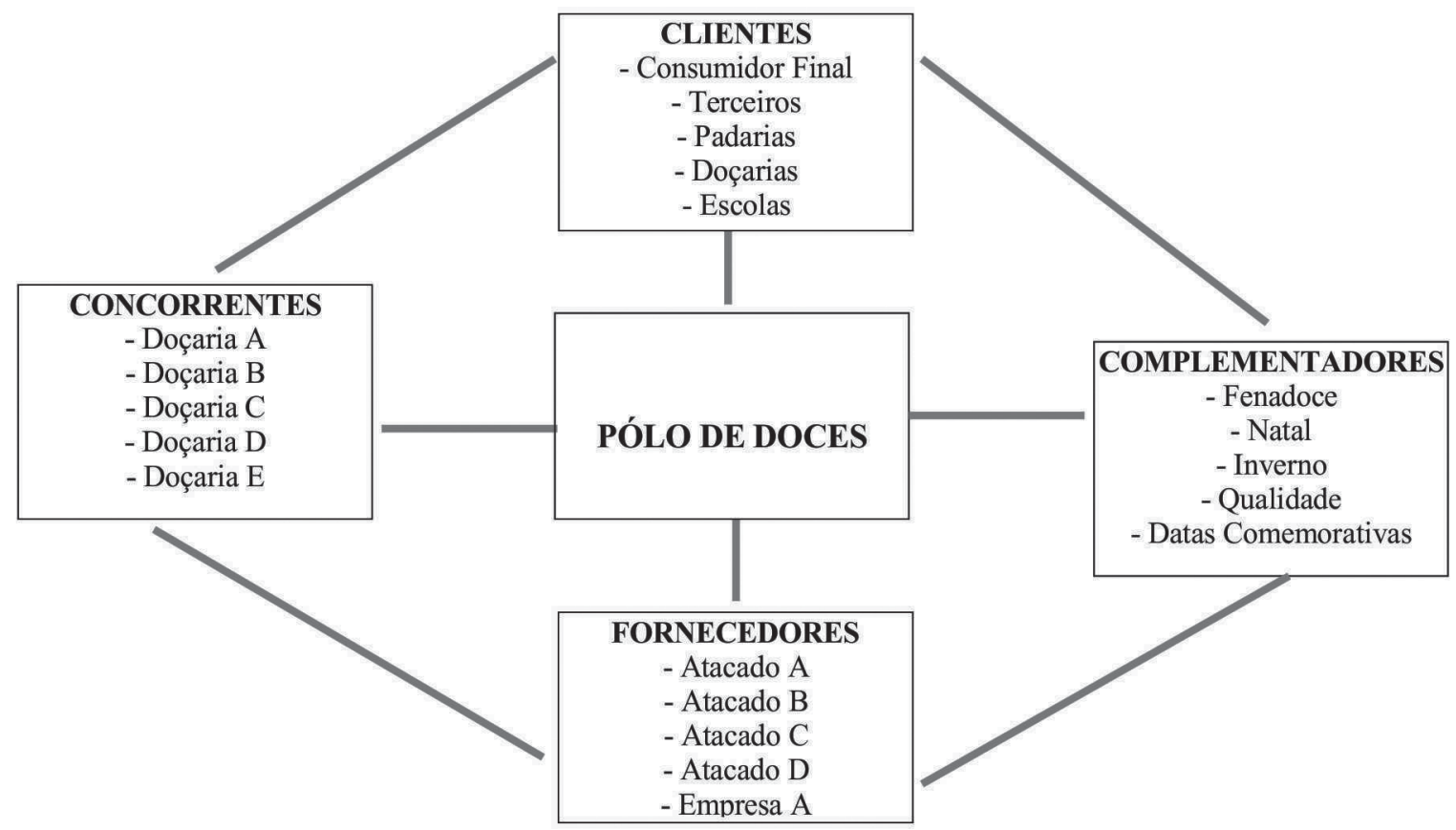

Figura 2: Rede de valor do Polo de Doces na concepção dos doceiros Fonte: Elaborado pelos autores

Doces tem como principais concorrentes os doceiros completamente informais, sem estrutura alguma $e$ que vendem o doce por um valor abaixo do mercado. Ainda, citaram algumas empresas de doces industrializados e produzidos em grande escala. Com relação aos principais fornecedores, as gestoras acreditam que a maioria compra em atacados e supermercados de Pelotas, porém as marcas basicamente não são de empresas da cidade e até mesmo do RS. Ressaltam que poucos doceiros fazem negociações diretamente com as empresas fornecedoras.

Como principais clientes, as entrevistadas argumentam que muitos doceiros vendem para outras cidades, como Porto Alegre e região da Serra, por exemplo. Também muitos vendem para uma terceira empresa (padaria, confeitaria, hotel, restaurante) que faz a venda final. Além disso, ressaltam que no caso de alguns doceiros a venda principal é doméstica ou até ambulante para o consumidor final. Com relação aos principais complementadores, as gestoras identificaram: site de venda de doces na internet, embalagem personalizada e interessante ao cliente e eventos como festas de casamento. Conforme relatado, as entrevistadas acreditam que a padronização do doce também pode ser um complementador, já que os doces vendidos em maiores volumes e para regiões diversas são os mais padronizados.

A equipe gestora também apontou a Fenadoce como complementador, porém ressaltam que a feira já não é mais o grande momento de vendas, uma vez que há alguns anos atrás o evento era considerado pelos doceiros como uma Feira de Negócios, uma vitrine, o que não acontece mais, pois um possível cliente não procura os doceiros mais na Feira, e sim diretamente na empresa ou até mesmo através de um site.

Analisando a rede de valor do Polo de Doces de Pelotas, verifica-se que existem alguns pontos que carecem de maior reflexão a partir dos conceitos de Nalebuff e Brandenburger (1996) a fim de se buscar estratégias coopetitivas para o Polo, que são:

a) Estratégias com clientes: os principais clientes identificados são o consumidor final, os terceiros/revendedores, as grandes doçarias, as escolas e outras cidades como Porto Alegre e região da Serra Gaúcha. Uma estratégia plausível neste caso parece ser evitar a venda informal $e$ os atravessadores, pois estes não contribuem em valor para o Polo. Ainda, outra 
estratégia seria buscar uma aproximação com hotéis, restaurantes e padarias e transformá-las em complementadores, ajudando a divulgar o produto, a sugerir melhorias em qualidade, padronização e conhecimento para o Polo, estabelecendo uma relação de soma não zero.

b) Estratégias com concorrentes: os principais concorrentes são os doceiros completamente informais e as grandes doçarias da cidade integradas ao Polo. Percebe-se que, no caso das grandes doçarias, estas são ora clientes, ora concorrentes e em alguns casos pertencem ao grupo. Uma estratégia para melhorar esta relação seria criar um acordo com estas doçarias para que se tornem parceiras dos menores empreendedores do Polo. Porém, para minimizar a questão, a estratégia mais adequada seria criar mecanismos impeditivos aos integrantes do Polo que negociam com estas doçarias, pois acabam criando uma concorrência para o grupo, e estimulam o oportunismo, fortalecendo jogos de soma zero.

c) Estratégias com fornecedores: os principais fornecedores são os atacados e os supermercados de Pelotas, porém as marcas basicamente não são de empresas da cidade e até mesmo do Estado. Uma estratégia coopetitiva seria desenvolver parceria com um número menor de fornecedores locais através de compras conjuntas, pois ao que parece estão muito segmentadas. Outra estratégia seria a compra direta de produtos de maior volume, junto à indústria, evitando assim o custo do atravessador.

d) Estratégias com complementadores: os principais complementadores identificados são a Fenadoce, outros eventos, datas comemorativas, épocas do ano, site de venda na internet e embalagem personalizada. Percebe-se que estratégias coopetitivas relacionando complementadores não são utilizadas, talvez por questões de cultura ou conhecimento. Vislumbrar clientes, fornecedores e concorrentes, como potenciais complementadores, seria a sugestão estratégica inicial. Em um segundo momento, sugere-se desenvolver acordos $e$ alianças entre os atores da rede de valor, dentro da lógica dos jogos de soma não zero, e após, consolidar estes acordos e alianças. Segundo Azevedo, Carvalho e Silva (2003) nos jogos de soma não zero, as ações dos jogadores irão modificar o valor adicionado global e a soma final dos payoffs não se mantém constante, o que acarretará na geração de vantagem competitiva para as empresas integrantes do Polo de Doces.

Essas reflexões procuram tangenciar a realidade do objeto de estudo e representam sugestões para a ponderação dos gestores e empresários do polo. $\mathrm{O}$ contexto competitivo atual apresenta desafios complexos ao mesmo tempo em que oferece oportunidades novas que podem ser aproveitadas a partir de uma visão estratégica.

\subsection{Capital Social do Polo de Doces de Pelotas - RS}

Para avaliar o capital social do Polo de Doces, analisam-se as seguintes dimensões: confiança, cooperação, comprometimento e conexões. Com relação

Tabela 5: Categoria Confiança

\begin{tabular}{|c|c|c|c|c|c|c|c|}
\hline \multirow{2}{*}{ Confiança } & \multicolumn{7}{|c|}{ INTENSIDADE (\%) } \\
\hline & Muita Baixa & BAIXA & MédIA & ALtA & Muito Alta & Não RESPosta & TOTAL \\
\hline \multicolumn{8}{|c|}{ Dimensão EXTERNA } \\
\hline Confiança entre os integrantes & 8,1 & 8,1 & 37,9 & 32,4 & - & 13,5 & 100 \\
\hline Confiança nos gestores & 2,7 & - & 16,2 & 37,9 & 29,7 & 13,5 & 100 \\
\hline Confiança percebida nos últimos meses & 2,7 & 10,8 & 37,9 & 29,7 & 5,4 & 13,5 & 100 \\
\hline \multicolumn{8}{|c|}{ DIMENSÃo INTERNA } \\
\hline Confiança inicial & 5,4 & 13,5 & 46,0 & 18,9 & - & 16,2 & 100 \\
\hline Confiança com o passar do tempo & 5,4 & - & 29,7 & 43,3 & 8,1 & 13,5 & 100 \\
\hline
\end{tabular}

Fonte: Dados da pesquisa 
à categoria confiança, Tabela 5 , percebe-se que, referente à dimensão externa da confiança, o maior nível relaciona-se aos gestores, evidenciando que os doceiros confiam mais nos gestores do que nos integrantes do Polo e isso se confirma também em relação a confiança percebida.

De modo geral, as duas dimensões da confiança demonstram um nível intermediário, evidenciando que o relacionamento do grupo ainda não atingiu um nível de confiança considerável. Contudo, existe a tendência da confiança aumentar com o passar do tempo.
Chin, Chan e Lam (2008) identificaram como um dos fatores críticos de sucesso para a gestão estratégia da coopetição, o desenvolvimento da confiança, sendo fundamental para a cooperação. Nesse sentido, ressalta-se a necessidade de uma maior confiança entre os integrantes do Polo de Doces.

Abordando a categoria cooperação (Tabela 6), destaca-se a contribuição para projetos que não proporcionam benefícios diretos, demonstrando que os integrantes do Polo de Doces apresentam uma alta predisposição em contribuírem com projetos que não lhes beneficiem diretamente.

Tabela 6: Categoria Cooperação

\begin{tabular}{|c|c|c|c|c|c|c|c|}
\hline \multirow{2}{*}{ COOPERAÇÃo } & \multicolumn{7}{|c|}{ INTENSIDADE (\%) } \\
\hline & Muito BaiXa & BAIXA & MÉDIA & Alta & Muito Alta & Não Resposta & TOTAL \\
\hline Ajuda mútua entre os integrantes & 13,5 & 10,8 & 37,9 & 21,6 & 2,7 & 13,5 & 100 \\
\hline Contribuição sem benefícios diretos & - & 2,7 & 10,8 & 37,9 & 35,1 & 13,5 & 100 \\
\hline Cooperação em situações de crise & 13,5 & 27,0 & 27,0 & 13,5 & 5,5 & 13,5 & 100 \\
\hline
\end{tabular}

Fonte: Dados da pesquisa

A ajuda mútua entre os integrantes foi classificada pela maioria dos respondentes como de média intensidade. O grau de cooperação em situações de crise foi avaliado entre baixo e médio. Isso exemplifica que quando os integrantes analisam a sua contribuição em projetos que não lhe trazem benefícios diretos avaliam como alta, porém quando a cooperação se relaciona aos demais integrantes classificam como média, demonstrando de modo geral, um nível intermediário de cooperação.
Tendo em vista que segundo Putnam (2005, p. 180) "a confiança promove a cooperação e quanto mais elevado o nível de confiança, maior a probabilidade de haver cooperação", evidenciou-se um nível intermediário tanto para a confiança como para a cooperação no Polo de Doces.

Os resultados da categoria comprometimento são apresentados na Tabela 7 .

Tabela 7: Categoria Comprometimento

\begin{tabular}{|c|c|c|c|c|c|c|c|}
\hline \multirow{2}{*}{ COMPROMETIMENTO } & \multicolumn{7}{|c|}{ INTENSIDADE (\%) } \\
\hline & Muito Baixa & BAIXA & MÉdia & Alta & Muito Alta & Não Resposta & TOTAL \\
\hline Envolvimento dos integrantes & 5,4 & 8,1 & 24,3 & 37,9 & 10,8 & 13,5 & 100 \\
\hline Envolvimento individual nas atividades & 10,8 & 10,8 & 21,6 & 24,3 & 19,0 & 13,5 & 100 \\
\hline Cumprimento das atividades - integrantes & - & 5,4 & 29,7 & 37,9 & 13,5 & 13,5 & 100 \\
\hline Cumprimento das atividades - individual & 8,1 & 2,7 & 24,3 & 32,4 & 19,0 & 13,5 & 100 \\
\hline
\end{tabular}

Fonte: Dados da pesquisa 
Todas as variáveis da categoria comprometimento foram avaliadas com um grau de intensidade alto pela maioria dos respondentes. Desse modo, constatou-se um comprometimento mais próximo de alto em relação à maioria dos integrantes do Polo, evidenciando que os membros do grupo apresentam um bom comprometimento em relação às reuniões e atividades, o que de acordo com Marchi (2006) evidencia o envolvimento $e$ interesse nas questões comuns do grupo.

As Tabelas 8, 9 e 10 mostram os resultados das questões relacionadas à dimensão conexões. A Tabela 8 apresenta o nível de bons relacionamentos e o grau de compartilhamento de informações entre os integrantes do Polo de Doces.

Tabela 8: Nível de bons relacionamentos e o grau de compartilhamento de informações

\begin{tabular}{|c|c|c|c|c|c|c|c|}
\hline \multirow{2}{*}{ CONEXões } & \multicolumn{7}{|c|}{ INTENSIDADE (\%) } \\
\hline & Muito Baixo & BaIxo & MÉDIO & Ацто & Muito Alto & Não Resposta & TOTAL \\
\hline Nível de bons relacionamentos & 8,1 & 2,7 & 18,9 & 51,4 & 5,4 & 13,5 & 100 \\
\hline $\begin{array}{l}\text { Grau de compartilhamento de } \\
\text { informações }\end{array}$ & 13,5 & 27 & 18,9 & 21,6 & 5,4 & 13,5 & 100 \\
\hline
\end{tabular}

Fonte: Dados da pesquisa

$\mathrm{O}$ nível de bons relacionamentos entre os integrantes do Polo é de modo geral alto, demonstrando que a maioria das pessoas se relaciona bem umas com as outras. O grau de compartilhamento de informações entre os integrantes do Polo é classificado pela maioria dos respondentes como baixo, o que pode restringir o número de conexões internas. A Tabela 9 mostra a frequência de contato entre os integrantes e de recebimento de informações sobre o do Polo.

Tabela 9: Contatos e recebimento de informações

\begin{tabular}{|c|c|c|c|c|c|c|}
\hline \multirow{3}{*}{ CONEXÕEs } & \multicolumn{6}{|c|}{ INTENSIDADE } \\
\hline & DiARIAMENTE & Semanalmente & Mensalmente & $\begin{array}{c}\text { MENOS DE UMA } \\
\text { VEZ POR MÊS }\end{array}$ & Não Resposta & TOTAL \\
\hline & $\%$ & $\%$ & $\%$ & $\%$ & $\%$ & $\%$ \\
\hline $\begin{array}{l}\text { Contato entre os } \\
\text { integrantes }\end{array}$ & 5,4 & 27 & 13,5 & 51,4 & 2,7 & 100 \\
\hline $\begin{array}{l}\text { Recebimento de } \\
\text { informações }\end{array}$ & 2,7 & 18,9 & 29,7 & 45,9 & 2,7 & 100 \\
\hline
\end{tabular}

Fonte: Dados da pesquisa

De acordo com a maioria dos respondentes a frequência dos contatos entre os integrantes ocorre menos de uma vez por mês, o que demonstra que os contatos entre os membros não são frequentes. A maior parte dos integrantes aponta que recebe informações a respeito do Polo de Doces menos de uma vez por mês, demonstrando que as informações não são recebidas com frequência, o que pode ocasionar falhas na comunicação.

$\mathrm{Na}$ Tabela 10, apresentam-se as conexões externas, isto é, as pessoas ou entidades citadas durante a pesquisa, que fornecem informações relevantes para os doceiros e não fazem parte do Polo de Doces. 
Tabela 10: Troca de informações externas

\begin{tabular}{|l|c|c|}
\hline \multicolumn{1}{|c|}{ CONEXõES EXTERNAS } & $\mathbf{F}(\mathbf{N})$ & $\mathbf{F}(\%)$ \\
\hline Não tem & 16 & 33,3 \\
\hline Fornecedores & 3 & 6,3 \\
\hline Concorrentes que não participam do Polo & 2 & 4,2 \\
\hline Familiares & 2 & 4,2 \\
\hline Internet & 2 & 4,2 \\
\hline Revistas & 2 & 4,2 \\
\hline Faculdades & 2 & 4,2 \\
\hline Outros & 19 & 39,6 \\
\hline Total & 48 & 100,0 \\
\hline
\end{tabular}

Fonte: Dados da pesquisa

Grande parte dos respondentes, 33,3\%, não troca informações com nenhuma pessoa ou entidade que não faça parte do Polo. O restante, representando $66,7 \%$ citou alguma pessoa ou entidade. Isso demonstra que alguns integrantes não possuem nenhuma conexão externa, enquanto outros apontam um número considerável de pessoas ou entidades.

$\mathrm{O}$ fator conexões se resume nos seguintes aspectos: com relação a sua dimensão interna, avalia-se como alto o nível de bons relacionamentos com a maioria dos integrantes do Polo e como baixo o grau de compartilhamento de informações entre os integrantes, demonstrando que as pessoas dizem se relacionar bem umas com as outras, porém consideram baixa a troca de informações entre os membros. A maior parte dos integrantes entra em contato com os demais membros do grupo e recebe informações a respeito do Polo menos de uma vez por mês. Por ser baixo o grau de compartilhamento de informações entre os integrantes, a frequência de contatos também é baixa. A frequência de recebimento de informações a respeito do Polo também é baixa, assim todos estes fatores podem estar causando falhas na comunicação entre o grupo.

No que se refere às conexões externas, grande parte dos integrantes não possui conexão com pessoas e entidades que não fazem parte do Polo, o que representa que as conexões externas estão restritas a alguns integrantes. Os achados denotam a necessidade de melhores relacionamentos internos e externos, tendo em vista que os bons relacionamentos internos e externos são destacados por Lipnack e Stamps (1994) e Burt (2001), pois viabilizam a coesão interna e a renovação das informações relevantes para a rede, aumentado a competitividade.

\section{Considerações Finais}

De acordo com as ideias de Castells (1999), as organizações e indivíduos estão socialmente envolvidos em teias e redes de relações, nas quais a cooperação consiste em um requisito indispensável. Essas conexões podem originar uma série de arranjos interorganizacionais, que se baseiam na valorização da produção local e na coopetição, uma vez que integram empresas competidoras que buscam conjuntamente vantagens competitivas baseadas na complementaridade, na criação de poder de compra de barganha, na ampliação da base técnica e de conhecimentos, que de maneira isolada talvez não fosse possível.

O presente trabalho analisou o Polo de Doces de Pelotas-RS e propôs reflexões estratégicas, a partir do mapeamento da sua rede de valor e da análise do seu capital social. Na visão de gestores e integrantes do polo, os clientes principais são o consumidor final e terceiros/revendedores; no que se referem aos fornecedores os atacados predominaram; com relação aos concorrentes os doceiros apresentam uma visão mais específica se referindo às outras empresas ligadas ao setor, enquanto os gestores já apontam uma preocupação com os doces industrializados e o comércio informal; relativo aos complementadores destaca-se na visão de ambos, a Fenadoce, ressalvando que os gestores indicam alguns fornecedores (internet e embalagens) como complementadores.

A partir do mapeamento da rede de valor do Polo, buscou-se refletir sobre possíveis contribuições em termos de estratégias coopetitivas, sugerindo-se: evitar a venda informal e os atravessadores; buscar uma aproximação com hotéis, restaurantes e padarias e transformá-las em complementadores, criar um acordo com grandes doçarias para que se tornem parceiras dos menores empreendedores do Polo; criar mecanismos impeditivos aos integrantes do Polo que negociam com as grandes doçarias; divulgar, conscientizar e oportunizar a associação no Polo; pressionar órgãos competentes para fiscalizar as atividades informais, desenvolver parcerias com um número menor de for- 
necedores locais através de compras conjuntas; comprar diretamente produtos em maior volume, junto as empresas produtoras; vislumbrar clientes, fornecedores e concorrentes como potenciais complementadores; oferecer acordos e alianças dentro da lógica do ganha-ganha; consolidar acordos e alianças.

As dimensões investigadas a respeito do capital social variam de baixas a altas, sendo que os contatos externos ao Polo foram identificados como baixos, caracterizando o que Burt (2001) chama de clausura. Características entre as opções nem baixo e nem alto $e$ alto, representaram a maior parte das dimensões do capital social. Isso representa que o Polo de Doces possui um nível intermediário de capital social, significando que ações são necessárias para consolidar o grupo. Caso não venham a ocorrer, este fato poderá inibir a confiança entre os membros e por consequência restringir futuras ações conjuntas do Polo. De acordo com Boisier (2000), o capital social representa justamente a confiança demonstrada entre os membros de um grupo para que possam cooperar na formação de novos grupos ou realizar ações em comum.

Em termos de contribuições, a partir das constatações da pesquisa, ressalte-se que o Polo de Doces, de certa forma, vem atingindo o seu objetivo, que consiste em promover e organizar o setor de doces de Pelotas, capacitar os empresários, melhorar a qualidade dos produtos e processos, articular ações conjuntas e consolidar projetos. Entretanto, no que se refere às contribuições estratégicas para facilitar o relacionamento entre os atores, um estímulo ao capital social pode impulsionar e aperfeiçoar o Polo de Doces, agindo nos pontos das dimensões apontadas pela pesquisa que estão em baixa ou que estão apenas em níveis medianos. Sugere-se: maior comunicação entre gestores e empresários, o que tende a elevar níveis de confiança; promover a integração dos participantes do Polo de Doces, a fim de criar a cultura da colaboração; divulgar o projeto aos empresários não atuantes no Polo, visando um incremento no número de empresários participantes; e sensibilizar integrantes do Polo em relação à importância do trabalho em conjunto com outras empresas do mesmo setor, possibilitando assim, um aperfeiçoamento e desenvolvimento do grupo.

A presente pesquisa apresentou como principais limitações, a dificuldade em mensurar e avaliar elementos subjetivos do capital social e a característica de corte transversal no tempo, limitando os resultados ao período da pesquisa. Para estudos futuros, sugerem-se abordagens que considerem o crescimento e o desenvolvimento das empresas a partir de séries temporais demonstrando a evolução da participação no Polo.

\section{ReferêNCIAS}

AMATO NETO, J. Redes de cooperação produtiva e clusters regionais: oportunidades para as pequenas $e$ médias empresas. São Paulo: Atlas: Fundação Vanzolini, 2000.

ARMSTRONG, J. S. Co-opetition. Journal of

Marketing, Canada, v. 61, n.2, p.92-99, apr.,1997.

AZEVEDO, G. M.; CARVALHO, H. F.; SILVA, J. F.

A Teoria dos jogos na estratégia de negócios: uma Contribuição Relevante? In: FIRST INTERNATIONAL CONFERENCE, 1, 1999, Madrid. Anais, Madrid: Iberoamerican Academy of Management, 1999.

BENGTSSON, M.; KOCK, S. Cooperation and Competition in relationships between competitors in business Networks. Journal of Business \& Industrial Marketing, New York, v. 14, n. 3, p. 178-194, 1999.

\section{BETEMPS, L. R. Vinhos e doces ao som de}

Marselha. Pelotas: Educat, 2003.

\section{BOISIER, S. Conversaciones sociales y desarrollo} regional. Talca: Editorial de la Universidad de Talca, 2000.

BORGATTI, S. P.; FOSTER P. C. The network paradigm in organizational research: a review and typology. Journal of Management, Londres, v. 29, n. 6, p. 991-1.013, May, 2003.

BRANDENBURGER, A. M.; NALEBUFF, B. J. Coopetição. Tradução de Alberto Lopes. Rio de Janeiro: Rocco, 1996.

BURT, R. S. Structural holes versus network closure as social capital. In: Social capital: theory and research. Edited by Nan Lin, Karen S. Cook and R S. Burt. New York: Aldine de Gruyter, 2001. 
CANEVER, M. D. et al. Sistema local de produção de doces artesanais de Pelotas: possibilidades de alavancagem. Revista Brasileira de Agrociência, Pelotas, v. 10, n. 1, p. 05-11, jan.-mar. 2004.

\section{CAPORALI, R.; VOLKER, P. (Org.). Metodologia de} desenvolvimento de arranjos produtivos locais: Projeto Promos - SEBRAE - BID: versão 2.0. Brasília: SEBRAE, 2004.

CASAROTTO, N. F; PIRES, L. H. Redes de pequenas e médias empresas e desenvolvimento local: estratégias para a conquista da competitividade global com base na experiência italiana. São Paulo: Atlas, 2001.

CASSIOLATO, J. E.; LASTRES, H. M. M. Novas políticas na era do conhecimento: o foco em arranjos produtivos e inovativos locais. Revista Parcerias Estratégicas, Brasília, n. 17, p. 5-26, set. 2003.

CASTELLS, M. A sociedade em rede. 2. ed. São Paulo: Paz e Terra, 1999.

CHIN, K. S.; CHAN, B. L.; LAM, P. K. Identifying and prioritizing critical success factors for coopetition strategy, Industrial Management \& Data Systems, Bingley, v. 108, n. 4, p. 437-454, 2008.

COLEMAN, James. Social Capital in the Creation of Human Capital. American Journal of Sociology, United States of America, v. 94, p. 95-120, 1988.

COSTA, E. A. Gestão estratégica: da empresa que temos para a empresa que queremos. 2. ed. São Paulo: Saraiva, 2007.

GARCIA, C. Q.; VELASCO, C. A. B. Co-opetition and Performance: evidence from European Biotechnology Industry. In: II Annual Conference of Euram on: “Innovative Research Management”. Track "Coopetition Strategy: Towards a new kind of interfirm dynamics". Stockholm: may 9-11, 2002.

GHEMAWAT, P. A estratégia e o cenário de negócios. 2. ed. Porto Alegre: Bookman, 2007.

GNYAWALI, Devi R.; PARK, Byung-Jin (Robert). Coopetition and Technological Innovation in Small and Medium-Sized Enterprises: a Multilevel Conceptual Model. Journal of Small Business Management, United States of America, v. 47, n. 3, p. 308-330, July, 2009.
GROOTAERT, C.; JONES, V. N.; NARAYAN, D.; WOOLCOCK, M. Measuring social capital: an integrated questionnaire. World Bank working paper; USA, n. 18, p. 1-53, novembro, 2003.

HAIR Jr., J. F. et al. Fundamentos de métodos de pesquisa em administração. Porto Alegre: Bookman, 2005.

LADO, A. A.; BOYD, N. G.; HANLON, S. C. Competition, Cooperation, and the Search for Economic Rents: a syncretic model. Academy of Management Review, United States of America, n. 1, p. 110-141, 1997.

LEONETI, A.; OLIVEIRA, S. V. W. B. de; OLIVEIRA, M. M. B. de. O equilíbrio de Nash como uma solução para o conflito entre eficiência e custo na escolha de sistemas de tratamento de esgoto sanitário com o auxílio de um modelo de tomada de decisão. Engenharia Sanitária e Ambiental, Rio de Janeiro, v. 15, n. 1, mar. 2010.

LIPNACK, J.; STAMPS, J. Rede de informações. São Paulo: Makron Books, 1994.

LODY, R. Doçaria brasileira: um doce sabor português. In: BOSISIO, Arthur (Coord.). A doçaria tradicional de Pelotas. Rio de Janeiro: SENAC Nacional, 2003. (p. 11-18)

MACKE, J.; DILLY, E. K. Social capital dimensions in collaborative networks: the role of linking social capital. International Journal of Social Inquiry, Turkey, v.. 3, n. 2, p. 121-136, 2010.

MAGALHÃES, M. O. de. A doce história de Pelotas. In: BOSISIO, Arthur (Coord.). A doçaria tradicional de Pelotas. Rio de Janeiro: SENAC Nacional, 2003. (p. 19-31)

MARCHI, J. J. Redes empresariais: um estudo comparativo dos fatores sócio-comportamentais e desempenho competitivo em duas redes de empresas do varejo alimentício. 2006. Dissertação (Mestrado em Administração) - Universidade Federal de Santa Maria. Santa Maria, 2006.

NEVES, M. P. S. das et al. Análise do processo de coopetição em redes horizontais de pequenas e médias empresas do Rio Grande do Sul. BASE - Revista de Administração e Contabilidade da Unisinos, São Leopoldo, v. 8, n. 3, p. 243-260, julho-setembro 2011. 
OLIVEIRA, L. de et al. Rede de Valor e Capital Social: ligando os conceitos por meio de um estudo de caso. In: III ENCONTRO DE ESTUDOS EM ESTRATÉGIA. Anais... São Paulo: ANPAD, 2007.

PODOLNY, J. M.; PAGE, K. L. Network forms of organization. Annual Review of Sociology, United States of America, v. 24, p. 57-76, 1998.

PORTER, M. E. Vantagem competitiva: criando e sustentando um desempenho superior. $11 \mathrm{ed}$. Rio de Janeiro: Campus, 1989.

PUTNAM, R. D. Comunidade e democracia: a experiência da Itália Moderna. Tradução Luiz Alberto Monjardim. 4. ed. Rio de Janeiro: FGV, 2005.

VINHAS, A. P. L. C.; BECKER, G. V. Redes de Cooperação interorganizacional: o caso da Rede MACSUL. Análise, Porto Alegre, v. 17, n. 1, p. 167-184, jan.-jul. 2006. Disponível em: <http://revistaseletronicas. pucrs.br>. Acesso em: 7 out. 2007.

WAIZBORT, R. Notas para uma aproximação entre o neodarwinismo $e$ as ciências sociais. História, Ciências, Saúde, Manguinhos, v. 12, n. 2, p. 293-318, maio-ago. 2005. 